\title{
A Comparison of Haemodynamic Responses between Clinical Assessments Guided Tracheal Intubation and Neuromuscular Block Monitoring Guided Tracheal Intubation
}

\author{
Nidhi Malipatil ${ }^{1}$, K. Harshavardhan ${ }^{2}$ \\ 1,2Department of Anaesthesiology, Father Muller Medical College, Mangalore, Karnataka, India.
}

\section{ABSTRACT}

\section{BACKGROUND}

During the induction of general anaesthesia (GA), laryngoscopy and endotracheal intubation produce significant nociceptive stimuli, which frequently results in inadvertent activation of the sympathetic nervous system. To blunt this pressor response, many drugs are successfully used. However, administration of an additional drug might cause adverse haemodynamic effects or might unnecessarily increase the depth of anaesthesia. Hence, a non-pharmacological measure to reduce the response is preferred. In this study, we wanted tocompare haemodynamic responses between clinical assessment-guided tracheal intubation and neuromuscular block monitoring-guided tracheal intubation.

\section{METHODS}

An observational study was conducted on 62 patients aged 18 - 60 years old belonging to American Soceity of Anaesthesiologist (ASA) I \& II posted for surgeries under general anaesthesia were allotted to 2 groups of 31 each. In Group C patients, the trachea was intubated after the clinical judgment of jaw muscle relaxation. In Group M patients, the trachea was intubated after train of four counts became zero in adductor pollicis muscle. Changes in heart rate [HR], mean arterial blood pressure [MAP], Krieg's intubation score, time between the administration of a neuromuscular blocking agent and endotracheal intubation were recorded. The collected data was analysed by mean, standard deviation, frequency, percentage, $\mathrm{t}$ test and chi square test.

\section{RESULTS}

HR and mean arterial pressure were significantly higher in Group C as compared to Group $\mathrm{M}$ after laryngoscopy and tracheal intubation $(P<0.05)$. The mean time required for intubation was significantly shorter in Group C compared to Group M $(179.52 \pm 2 \mathrm{~s}$ vs. $358.19 \pm 55 \mathrm{~s})$. Excellent and good intubation conditions were observed in all Group M patients, whereas 24 out of 31 patients (77 \%) in Group C showed excellent and good intubation conditions.

\section{CONCLUSIONS}

Haemodynamic responses to laryngoscopy and tracheal intubation can be significantly attenuated if tracheal intubation is performed following complete paralysis of laryngeal muscles, detected by neuromuscular monitoring of adductor pollicis muscle.

\section{KEY WORDS}

Laryngoscopy, Intubation, Haemodynamic Responses, Stress Response, Neuromuscular Monitor.
Corresponding Author: Dr. K. Harshavardhan, Associate Professor, Department of Anaesthesia, Father Muller Medical College, Mangalore, Karnataka, India.

E-mail: harshaomega@gmail.com

DOI: $10.14260 /$ jemds/2021/804

How to Cite This Article: Malipatil N, Harshavardhan K. A comparison of haemodynamic responses between clinical assessments guided tracheal intubation and neuromuscular block monitoring guided tracheal intubation. J Evolution Med Dent Sci 2021;10(45):3983-3987, 10.14260/jemds/2021/804

Submission 04-11-2021,

Peer Review 09-12-2021,

Acceptance 15-12-2021,

Published 28-12-2021.

Copyright (c) 2021 Nidhi Malipatil et al. This is an open access article distributed under Creative Commons Attribution License [Attribution 4.0 International (CC BY 4.0)] 


\section{BACKGROUND}

During the induction of general anaesthesia, laryngoscopy and endotracheal intubation produce significant nociceptive stimuli, which frequently results in inadvertent activation of the sympathetic nervous system. ${ }^{1}$ In general, the cardiovascular changes that occur as a result of intubation are temporary and have no long-term consequences. Exaggerated haemodynamic parameters, on the other hand, might lead to myocardial ischaemia or secondary brain injury in individuals with concurrent coronary artery disease, arterial hypertension, or intracranial pathology. Many drugs have been effectively used to reduce the pressor response. ${ }^{2}$ An extra drug, on the other hand, might have negative haemodynamic effect or enhance the degree of anaesthesia needlessly. As a result, a non-pharmacological approach of lowering the reaction is preferred.

The level of circulatory response is determined by the kind and depth of general anaesthesia used, the patient's age, the presence of diabetes, cardiovascular or other systemic disorders, and the medications employed. ${ }^{2}$ This reaction is also influenced by the duration of laryngoscopy and intubation, as well as the procedure's ease of execution. ${ }^{3,4}$ To obtund sympathetic response, it is critical to obtain sufficient neuromuscular block with neuromuscular blocking drugs. Neuromuscular blockade (NMB) should be monitored throughout the anaesthetic procedure, particularly during induction and recovery. Whenever there is a need for the muscle relaxation in order to achieve clinically acceptable intubation conditions or to reduce the possibility of upper airway injury, this type of monitoring is preferable. ${ }^{5,6}$ Despite the fact that the peripheral nerve stimulator was discovered 50 years ago, only around $10 \%$ of anesthesiologists employ objective neuromuscular blockade monitoring in routine clinical practise.7,8 NMB monitoring is important especially during anaesthesia induction in order to determine the best intubation time, guarantee proper intubation circumstances, and limit the hemodynamic response to laryngoscopy and tracheal tube placement.

We aimed at evaluation of neuromuscular block monitoring in preventing haemodynamic fluctuations following laryngoscopy and tracheal intubation after administration of vecuronium in comparison to clinical assessment of timing of laryngoscopy and tracheal intubation.

\section{Aim of the Study}

To compare haemodynamic responses between clinical assessment-guided tracheal intubation and neuromuscular block monitoring-guided tracheal intubation.

\section{Objectives of the Study}

a) Primary objective - To assess HR changes in response to tracheal intubation.

b) Secondary objectives

a. To assess changes in mean arterial pressure in response to intubation and intubating conditions as graded using the Krieg's intubating score.

b. To assess time between the administration of a neuromuscular blocking agent and endotracheal intubation.

\section{METHODS}

This study was an observational study among patients admitted for elective surgeries at Father Muller Medical College Hospital, Mangalore, Karnataka from November 2020 to October 2021.

\section{Inclusion Criteria}

1. Patients scheduled for elective surgery under general anesthesia.

2. Age between 18 and 60 years of either sex.

3. ASA physical status classes I and II.

\section{Exclusion Criteria}

1. Patient refusal to take part in the study.

2. Anticipated difficult intubation.

3. Patients with hepatic, renal, cardiovascular, neurological and muscular disorders.

4. Other systemic diseases such as diabetes mellitus, hypertension.

5. Patients on antipsychotic medications.

\section{Sample Size Calculation}

Total of 62 patients, i.e; 31 patients in each group.

The following formula was used to obtain the sample size ' $n$ '

$n=\frac{2\left(Z_{\alpha}+Z_{\beta}\right)^{2} \sigma^{2}}{\left(\overline{x_{1}}-\overline{x_{2}}\right)^{2}}$

$Z_{\alpha}=1.96$ at $95 \%$ C.I

$Z_{\beta}=0.841$ at $80 \%$ power

$\left(\overline{x_{1}}-\overline{x_{2}}\right)^{2}=10$ beats $/ \mathrm{min}$

$\sigma=14$ beats $/ \mathrm{min}$

$\mathrm{n}=31$ per group at $80 \%$ power

This sample size is chosen from a study done by Witkowska M et al. ${ }^{9}$

\section{Methodology}

Following approval of the Institutional Ethics Committee, sixty two normotensive patients of status ASA grade 1 and 2 between age 18 - 60 years old, undergoing elective surgeries under general anaesthesia were included in the study. Preoperative evaluation of the patient was done on the day before surgery. After taking written and informed consent, indication for surgery, baseline heart rate and blood pressure were noted. Basic appropriate investigations like $\mathrm{Hb}$, complete blood count (CBC), serum urea and creatinine, blood sugar, urine examination, chest $\mathrm{X}$-ray and electrocardiogram (ECG) were done. Patients were advised 6 - 8 hours fasting prior to surgery and received tablet pantoprazole $40 \mathrm{mg}$ on morning of surgery. In the operating room, monitors including 3-lead electrocardiogram, noninvasive blood pressure (NIBP), pulse oximeter, neuromuscular monitor (train of four [TOF] watch) were attached, and baseline vitals were recorded. Peripheral venous access was secured. Patients were pre-oxygenated for 
3 minutes with $100 \%$ Fi02, premedicated with Inj. fentanyl 2 $\mathrm{mcg} / \mathrm{kg}$ induced with Inj. propofol $2 \mathrm{mg} / \mathrm{kg}$ till the loss of response to verbal commands. Then, a supramaximal TOF stimulus was applied to the ulnar nerve at the wrist through surface electrodes (stimulation current set at $60 \mathrm{~mA}$ ). Baseline TOF ratio percentage wias noted. After standardisation of supramaximal stimulus intravenous vecuronium $0.1 \mathrm{mg} / \mathrm{kg}$ was administered over $5 \mathrm{~s}$. After the administration of the vecuronium, lungs were ventilated with sevoflurane in $100 \%$ oxygen till the tracheal intubation.

Total of 62 patients pre decided by anaesthesiologist outside the research team will be observed and studied-

Group C ( $\mathrm{n}=31)$ - The trachea was intubated following clinical assessment of neuromuscular blockade.

Group M ( $\mathrm{n}=31)$ - The trachea was intubated following neuromuscular block monitoring by TOF WatchTM.

In Group C, the timing of intubation was judged based on clinical assessment starting at $1 \mathrm{~min}$ after administration of muscle relaxant and at every $30 \mathrm{~s}$ thereafter by an experienced anaesthesiologist. The timing of laryngoscopy was based on ease of ventilation, jaw and upper airway tone. Jaw tone was assessed by attempting to open patient's mouth, whereas upper airway tone was determined by amount of jaw support necessary to maintain patent airway. In Group M, intubation was done after complete loss of all 4 responses to TOF stimulation (TOF count zero), carried out every $30 \mathrm{~s}$ starting at $1 \mathrm{~min}$ after administration of vecuronium. The electrical stimulation was done with $60 \mathrm{~mA}, 2 \mathrm{~Hz}$ current lasting $0.2 \mathrm{~ms}$. The trachea was intubated with endotracheal tubes of appropriate sizes. The cuff of the endotracheal tube was inflated over $5 \mathrm{~s}$. The time from administration of neuromuscular blocking drugs to the time of tracheal intubation and cuff inflation was noted. Thereafter, mechanical lung ventilation was carried out using sevoflurane in oxygen : nitrous oxide $(40: 60)$ mixture. The ventilator parameters were adjusted to maintain end-tidal carbon dioxide ranging from 36 to $40 \mathrm{~mm} \mathrm{Hg}$.

\section{Statistical Analysis}

The collected data was analysed by mean, standard deviation, frequency, percentage, t-test and chi square test.

\section{RESULTS}

There was no statistical significance between the two groups with respect to age, gender and weight with no statistical as shown in Figure 1 and Table 1.



\begin{tabular}{|c|c|c|c|c|c|c|}
\hline & Group & $\mathbf{N}$ & Mean & Std. Deviation & $\begin{array}{l}\text { t Test p } \\
\text { Value }\end{array}$ & \\
\hline \multirow{2}{*}{ Age } & Group C & 31 & 39.29 & 7.708 & \multirow{2}{*}{.611} & \multirow{2}{*}{ NS } \\
\hline & Group M & 31 & 38.23 & 8.651 & & \\
\hline \multirow{2}{*}{ Weight } & Group C & 31 & 57.52 & 5.434 & \multirow{2}{*}{.054} & \multirow{2}{*}{ NS } \\
\hline & Group M & 31 & 54.16 & 6.669 & & \\
\hline
\end{tabular}

Comparison of mean heart rate and mean arterial pressure between the two groups was statistically significant at the $\mathrm{T} 3, \mathrm{~T} 4, \mathrm{~T} 5$, and $\mathrm{T} 6$ time points, $(\mathrm{P}<0.05)$, indicating that the mean HR and mean arterial pressure increased in Group C after laryngoscopy and tracheal intubation in comparison to Group M; (Figure $2 \& 3$ )
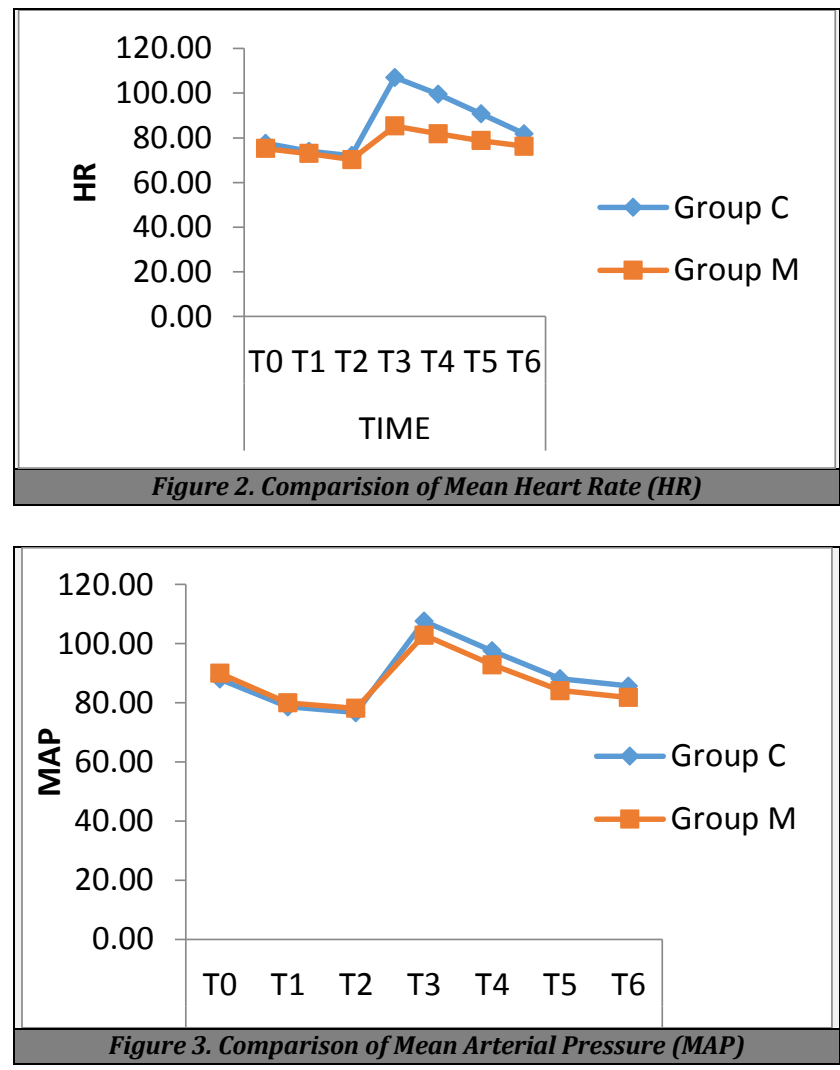

T0 - Before shifting the patient to OT table (baseline data); T1 - Immediate after vecuronium administration; T2 1 min after vecuronium administration; T3 - After inflation of the cuff following intubation; T4 - 1 min after intubation; T5 - 3 min after intubation; T6 - 5 min after intubation.

The mean time from administration of neuromuscular blocking agent and tracheal intubation was significantly higher in Group M as compared to Group C $(P<0.05)$ [Table $2]$. The intubating score was better in Group $M$ as compared to Group C $(P=0.01)$

\begin{tabular}{|cccc|}
\hline Parameters & Group C & Group M & P \\
\hline $\begin{array}{c}\text { 1.Time between the administration of a } \\
\text { neuromuscular blocking agent and endotracheal } \\
\text { intubation(secs) }\end{array}$ & 179.52 & 358.19 & 0.00 \\
$\begin{array}{c}\text { 2. Intubating condition } \\
\text { (Krieg's intubation score 3:4:5) }\end{array}$ & $14: 10: 7$ & $25: 6: 0$ & 0.01 \\
\hline \begin{tabular}{c} 
Table 2. Study Parameters in the Two Groups \\
\hline
\end{tabular}
\end{tabular}

Intubating condition $3 \& 4$ are considered as favorable intubation. 


\section{DISCUSSION}

We observed from the study that the neuromuscular monitoring-based timing for tracheal intubation causes lesser haemodynamic surge as compared to clinical-based timing for tracheal intubation. Furthermore, the intubating condition was better in the neuromuscular monitor guided group where timing of laryngoscopy was guided as compared to conventional clinical assessment-based timing.

Laryngoscopy and endotracheal intubation can cause profound changes in haemodynamics and intracranial pressure, probably as a result of intense sympathetic nervous system stimulation. These cardiovascular effects can be reduced using various pharmacological drugs. ${ }^{10,11}$ The effects of these drugs may last long after the laryngoscopy and tracheal intubation stimulation ceases, resulting in subsequent haemodynamic variations. This is why a nonpharmacological method to avoid the surge is so important. Many studies have demonstrated that the duration of laryngoscopy and intubation, as well as the ease of the intubation technique affects the haemodynamic response. 3,4 To avoid activation of the sympathoadrenergic system, it is necessary to achieve optimal neuromuscular blockade with a muscle relaxant. As a result, assessing full neuromuscular blockade appears to be necessary for optimum intubation time. The response to TOF stimulation was used to determine if total paralysis was achieved. The laryngeal muscles are considered totally paralysed when the TOF count reaches zero. When the TOF watch displayed "zero count" following TOF electrical stimulation, intubation was done in the neuromuscular monitoring group (M).

In our study, patients who were intubated based on clinical evaluation had higher mean HR and mean arterial pressure during and after intubation than patients who were intubated based on neuromuscular monitoring ( $P$ 0.05) seen in figure $2 \& 3$. The mean time for endotracheal intubation was more and intubating conditions were better in patients who were intubated based on neuromuscular monitor compared to clinical assessment seen in table 2 .

\section{This is Comparable to the Following Studies}

Nandi et al. concluded that using NMB monitoring offer more satisfactory intubating conditions comparing to clinical judgement as well as attenuated hemodynamic response to laryngoscopy and intubation. ${ }^{12}$

Witkowska et al. showed that more time was required for intubation when NMB monitoring is used, but with better intubation conditions and minimal cardiovascular response. ${ }^{9}$

Smith et al. showed that clinical judgement underestimated the time required for adequate onset of action of vecuronium, resulting in less favourable intubating conditions. ${ }^{13}$

In our study, the adductor pollicis muscle was used to detect the neuromuscular block. The TOF count in the orbicularis oculi muscle drops to zero faster than the adductor pollicis muscle when neuromuscular blocking drugs are administered. ${ }^{44,15}$ As a result, if the orbicularis oculi muscle was chosen for monitoring, early intubation is possible. In certain cases, however, inadequate intubation conditions were found. It has also been reported that when the adductor pollicis is evaluated during tracheal intubation, all patients have a better intubation condition.9,16,17 The adductor pollicis muscle was chosen for monitoring in this investigation because favourable intubation condition helps to decrease the haemodynamic surge. It is also easy to monitor because it is a peripheral muscle.

In comparison to clinical assessment, we found that neuromuscular monitoring guidance provided more satisfactory intubating conditions. We found intubation score 3 or 4 (excellent or good intubation circumstances) in all 31 patients in the neuromuscular monitored group. Only 24 of the 31 patients in the clinically guided group (77 percent) had acceptable or outstanding intubation conditions. As a result, all patients had good intubation circumstances when the time of intubation was chosen after full cessation of the reaction to TOF stimulation, as measured visually and by acceleromyography. According to the literature, 95 percent to 100 percent of patients were given favourable intubation conditions based on the same assessment of the response to supramaximal TOF ulnar nerve stimulation.9,16 As a result, in the vast majority of situations, this approach appears to be enough for ensuring ideal intubation circumstances.

Anaesthesiologists do not routinely use a neuromuscular monitor during endotracheal intubation. It is mostly used to monitor muscle relaxation during operational procedures and to identify any residual paralysis thereafter. As a result, further neuromuscular monitoring during intubation study is needed.

\section{CONCLUSIONS}

When tracheal intubation is done after complete paralysis of the laryngeal muscles, as detected by neuromuscular block monitoring of the adductor pollicis muscle, the haemodynamic responses to laryngoscopy and tracheal intubation are significantly reduced when compared to conventional time-based clinical assessment. In addition, when endotracheal intubations are undertaken after neuromuscular monitoring, the intubating circumstances improve.

\section{Limitations of the Study}

The time gap between fentanyl administration and endotracheal intubation is different in two groups. This might have had a role in the differences in haemodynamic response between the two groups.

Data sharing statement provided by the authors is available with the full text of this article at jemds.com.

Financial or other competing interests: None.

Disclosure forms provided by the authors are available with the full text of this article at jemds.com.

\section{REFERENCES}

[1] Kazama T, Ikeda K, Morita K. Reduction by fentanyl of the $\mathrm{Cp50}$ values of propofol and hemodynamic responses to various noxious stimuli. Anesthesiology 1997;87(2):213-27. 
[2] Kovac AL. Controlling the hemodynamic response to laryngoscopy and endotracheal intubation. J Clin Anesth 1996;8(1):63-79.

[3] Angelard B, Debry C, Planquart X, et al. Difficult intubations. A prospective study. Ann Otolaryngol Chir Cervicofac 1991;108(4):241-3.

[4] Morgan JM, Barker I, Peacock JE, et al. A comparison of intubating conditions in children following induction of anaesthesia with propofol and suxamethonium or propofol and remifentanil. Anaesthesia 2007;62(2):1359.

[5] Sardesai AM, Griffiths R. Monitoring techniques: neuromuscular blockade. Anesth Intensive Care Med 2005;6(6):198-200.

[6] Mencke T, Echternach M, Plinkert PK, et al. Does the timing of tracheal intubation based on neuromuscular monitoring decrease laryngeal injury? A randomized, prospective, controlled trial. Anesth Analg 2006;102(1):306-12.

[7] Grayling M, Sweeney BP. Recovery from neuromuscular blockade: a survey of practice. Anaesthesia 2007;62(8):806-9.

[8] Della Rocca G, Iannuccelli F, Pompei L, et al. Neuromuscular block in Italy: a survey of current management. Minerva Anestesiol 2012;78(7):767-73.

[9] Witkowska M, Karwacki Z, Wierzchowska J, et al. Neuromuscular block monitoring for optimisation of conditions for endotracheal intubation. Anestezjol Intens Ter 2009;41(3):140-4.

[10] Safavi M, Honarmand A. Attenuation of cardiovascular responses to laryngoscopy and tracheal intubation-- intravenous sufentanil vs. pethidine. Middle East J Anaesthesiol 2008;19(6):1349-59.

[11] Fassoulaki A, Melemeni A, Paraskeva A, et al. Gabapentin attenuates the pressor response to direct laryngoscopy and tracheal intubation. Br J Anaesth 2006;96(6):769-73.

[12] Nandi R, Basu SR, Sarkar S, et al. A comparison of haemodynamic responses between clinical assessmentguided tracheal intubation and neuromuscular block monitoring-guided tracheal intubation: a prospective, randomised study. Indian J Anaesth 2017;61(11):910-5.

[13] Smith I, Saad RS. Comparison of intubating conditions after rocuronium or vecuronium when the timing of intubation is judged by clinical criteria. Br J Anaesth 1998;80(2):235-7.

[14] Debaene B, Beaussier M, Meistelman C, et al. Monitoring the onset of neuromuscular block at the orbicularis oculi can predict good intubating conditions during atracurium-induced neuromuscular block. Anesth Analg 1995;80(2):360-3.

[15] Plaud B, Laffon M, Ecoffey C, et al. Monitoring orbicularis oculi predicts good intubating conditions after vecuronium in children. Can J Anaesth 1997;44(7):7126.

[16] Haller G, Gardaz JP, Bissonnette B. Assessment of intubation time and conditions under the influence of rocuronium. Can J Anaesth 1998;45(4):312-6.

[17] Cheng KI, Chu KS, Chen WC, et al. The train of four ratio decreases to zero in anesthetized children is the guide to achieve a satisfactory intubation condition. Kaohsiung J Med Sci 2002;18(1):23-9. 